\title{
Progressive, Seizure-Like, Spike-Wave Discharges Are Common in Both Injured and Uninjured Sprague-Dawley Rats: Implications for the Fluid Percussion Injury Model of Post-Traumatic Epilepsy
}

\author{
Krista M. Rodgers, ${ }^{1}$ F. Edward Dudek, ${ }^{2}$ and Daniel S. Barth ${ }^{1}$ \\ ${ }^{1}$ Department of Psychology and Neuroscience, University of Colorado, Boulder, Colorado 80309, and ${ }^{2}$ Department of Neurosurgery, University of Utah \\ School of Medicine, Salt Lake City, Utah 84108
}

\begin{abstract}
Variable-duration oscillations and repetitive, high-voltage spikes have been recorded in the electrocorticogram (ECoG) of rats weeks and months after fluid percussion injury (FPI), a model of traumatic brain injury. These ECoG events, which have many similarities to spike-wave-discharges (SWDs) and absence seizures, have been proposed to represent nonconvulsive seizures characteristic of posttraumatic epilepsy (PTE). The present study quantified features of SWD episodes in rats at different time points after moderate to severe FPI, and compared them with age-matched control rats. Control and FPI-injured rats at 1 year of age displayed large-amplitude and frequent SWD events at frontal and parietal recording sites. At 3-6 months, SWDs were shorter in duration and less frequent; extremely brief SWDs (i.e., "larval") were detected as early as 1 month. The onset of the SWDs was nearly always synchronous across electrodes and of larger amplitude in frontal regions. A sensory stimulus, such as a click, immediately and consistently stopped the occurrence of the SWDs. SWDs were consistently accompanied by behavioral arrest. All features of SWDs in control and experimental (FPI) rats were indistinguishable. None of the FPI-treated rats developed nonconvulsive or convulsive seizures that could be distinguished electrographically or behaviorally from SWDs. Because SWDs have features similar to genetic absence seizures, these results challenge the hypothesis that SWDs after FPI reflect PTE.
\end{abstract}

Key words: absence; acquired epilepsy; epilepsy; fluid percussion; genetic epilepsy; seizure

\section{Introduction}

Traumatic brain injury (TBI) is a common cause of acquired epilepsy (vs genetic epilepsy), characterized by spontaneous, recurrent seizures that are often focal and nonconvulsive, but can spread and undergo secondary generalization to become convulsive (Agrawal et al., 2006; Engel, 2013). Post-traumatic epilepsy (PTE) is often intractable, so developing strategies to prevent or treat PTE would benefit from appropriate animal models. One of the most common animal models of TBI is fluid percussion injury (FPI) in Sprague-Dawley rats (D'Ambrosio et al., 2004; Kharatishvili et al., 2006), mimicking closed head injury in humans (Thompson et al., 2005). However, well documented evidence of spontaneous recurrent seizures resulting from TBI that

\footnotetext{
Received March 9, 2015; revised April 19, 2015; accepted May 10, 2015.

Author contributions: K.M.R. and D.S.B. designed research; K.M.R. and D.S.B. performed research; K.M.R., F.E.D., and D.S.B. analyzed data; K.M.R., F.E.D., and D.S.B. wrote the paper.

This work was supported by the US Army Medical Research and Material Command (Grant PR100040).

F.E.D. has equity interest in and receives consultant fees from Epitel, which is a company that makes telemetric recording devices; however, this work did not use these devices. The remaining authors declare no competing financial interests.

Correspondence should be addressed to Dr Daniel S. Barth, Department of Psychology and Neuroscience, University of Colorado, Campus Box 345, Boulder, C0 80309. E-mail: daniel.barth@colorado.edu.

DOI:10.1523/JNEUROSCI.0919-15.2015

Copyright $\odot 2015$ the authors $\quad 0270-6474 / 15 / 359194-11 \$ 15.00 / 0$
}

are distinctly different from normal rhythmic or oscillatory events in control animals is limited (Kharatishvili et al., 2006; Statler et al., 2009; Shultz et al., 2013; Campbell et al., 2014). Considerable debate has occurred on what constitutes an epileptic seizure that could form the basis for a model of PTE (D'Ambrosio and Miller, 2010; Dudek and Bertram, 2010), and investigations of mechanisms and intervention strategies for PTE, with unequivocal epileptic seizures, are lacking.

Previous studies using rostral parasagittal FPI report that injury-induced, electrocortically and behaviorally distinct, seizure-like events are never observed in sham-operated controls (D'Ambrosio et al., 2004, 2009), suggesting that they are specific to FPI-treated rats and thus represent PTE. The interpretation that these postinjury events are epileptic seizures is surprising given that their electrographic and behavioral characteristics appear identical to those described for high-voltage rhythmic spiking, which are labeled spike-wave-discharge (SWD) in uninjured rats, including the Sprague-Dawley breed (Aldinio et al., 1985; Kleinlogel, 1985; Buzsáki et al., 1990b; Kelly et al., 2001; Kharlamov et al., 2003; Pearce et al., 2014) used in previous FPI experiments. SWD are quasiperiodic signals having unique spectra with high values at a fixed fundamental frequency $(7-9 \mathrm{~Hz}$ for SWD) and at whole multiples (harmonics) of this fundamental frequency. These spectral characteristics so distinctly identify 


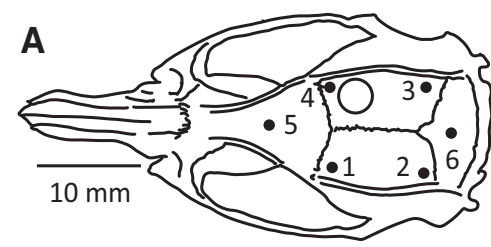

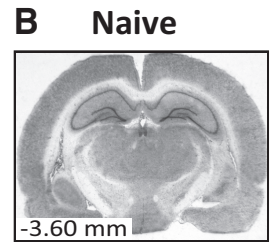

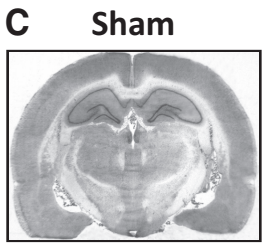

$4.0 \mathrm{~mm}$

$E$

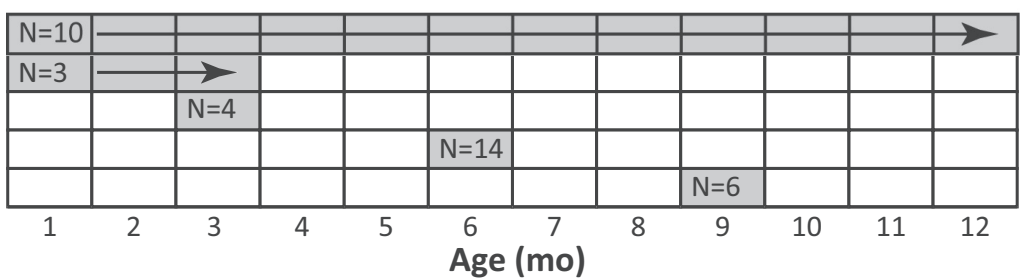

$F$

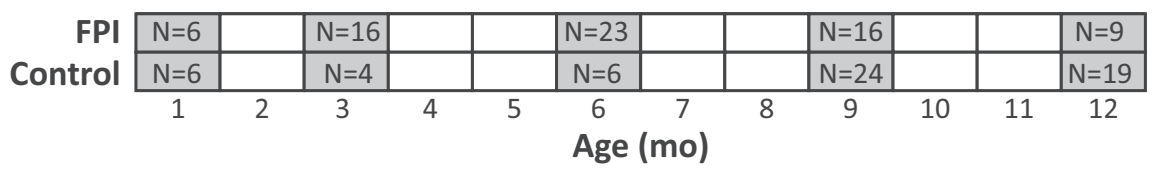

Figure 1. ECOG montage and FPI histology. $A$, Craniotomy for FPI (open circle) in relation to rostral ( 1 and 4 ) and caudal ( 2 and 3) recording sites. Reference and ground electrodes are 5 and 6 , respectively. Cresyl violet stained coronal sections comparing a control ( $\boldsymbol{B}$ ) and sham $(\boldsymbol{C})$ to damage typically induced by $\mathrm{FPI}(\boldsymbol{D})$ at 5 months postinjury. Just caudal to the craniotomy, FPl induced marked structural damage, cortical atrophy, deformation, atrophy and asymmetry of the hippocampus (arrows), and ventricular enlargement. "ipsi" and "contra" refer to ipsilateral and contralateral to injury site, respectively. $\boldsymbol{E}$, Age distribution of FPI rats undergoing continuous video/ECoG monitoring for seizure and epileptiform spike detection. $\boldsymbol{F}$, Age distribution of FPI and control rats for SWD quantification.

SWD (Shaw, 2004) that they have been used for automated SWD detection (Van Hese et al., 2003, 2009). They are also exactly the same as those described for cortical discharge produced by rostral parasagittal FPI (D'Ambrosio et al., 2004). Additionally, normal SWDs are invariably associated with behavioral arrest and facial automatisms (Vanderwolf, 1975; Hammond et al., 1979; Robinson and Gilmore, 1980; Semba et al., 1980; Vergnes et al., 1982; Kaplan, 1985; Shaw, 2004), also noted as a unique characteristic of seizures in FPI rats. The common presence of SWD and associated behavioral arrest in uninjured Sprague Dawley rats raises the possibility of confounds in the interpretation of results from PTE models if they are thought to also reflect seizures. The present study visually examined continuous video/ electrocorticogram (ECoG) recordings for possible seizures and also quantified features of SWD episodes in control rats between 1 and 12 months of age using automated procedures, with the objective of distinguishing normal brain activity from that associated with PTE. These results were compared with the same timeline in brain-injured rats receiving moderate and severe rostral parasagittal FPI.

\section{Materials and Methods}

Ninety adult viral-free male Sprague-Dawley rats (Harlan Laboratories) were housed in pairs in temperature $\left(23 \pm 3^{\circ} \mathrm{C}\right)$ and light $(12 \mathrm{~h}$ light/ dark) controlled rooms with ad libitum access to food and water. All procedures were performed in accordance with University of Colorado Institutional Animal Care and Use Committee guidelines for the humane use of laboratory rats in biological research. Rats were randomly assigned to the following groups: sham operated $(n=20)$, naive $(n=20)$, FPImoderate $(n=15)$, and FPI-severe $(n=35)$.

Fluid percussion injury and experimental groups. The rostral parasagittal FPI used in this study were described previously (D'Ambrosio et al., 2004; Frey et al., 2009; Rodgers et al., 2012). Briefly, FPI rats were anesthetized with halothane (Abbott Laboratories; $3.5 \%$ induction, $1.5-2.0 \%$ maintenance) and mounted in a stereotaxic frame. A 3.0-mm-diameter craniotomy was centered at AP $-2.0 \mathrm{~mm}$ and ML $3.0 \mathrm{~mm}$ from the midsagittal suture (Fig. $1 \mathrm{~A}$ ), with the exposed dura remaining intact. A female LuerLoc hub (inside diameter of $3.5 \mathrm{~mm}$ ) was secured over the craniotomy with cyanoacrylate adhesive. Following hub implantation, rats were removed from the stereotaxic frame and connected to the FPI apparatus, and after recovering from anesthesia sufficiently that the forepaw withdrawal reflex could be elicited, the impact was delivered. The FPI apparatus delivered one of two impact pressures (10 ms pulse), either an impact force of 2.0 or $3.4 \mathrm{~atm}$ (moderate or severe injury, respectively). All rats experienced apnea following injury and were revived after $15 \mathrm{~s}$. The injury cap was then removed, scalp sutured, and the rats returned to their home cages for recovery. The righting time was $\sim 10$ min following injury. There was a $\sim 10 \%$ mortality rate for severe impact pressures. Sham-operated rats underwent identical surgical preparation, but did not receive the brain injury. Naive rats only received electrode implantation surgery described below.

Chronic video/ECoG recording. One week following FPI or sham surgery, epidural bilateral stainless steel screw electrodes were implanted for ECoG recording, using septic surgical procedures for all chronic preparations. Under halothane anesthesia (3.5\%), rats were implanted with bilateral screw electrodes ipsilateral and contralateral to injury (Fig. 1A) over parietal (AP $-6.0 \mathrm{~mm}$, ML $4.5 \mathrm{~mm}$ ) and frontal (AP $0 \mathrm{~mm}$, ML 4.5 $\mathrm{mm}$ ) cortex, a reference screw (AP $3.0 \mathrm{~mm}, \mathrm{ML} 1.0 \mathrm{~mm}$ ), and a ground screw (AP $-7.5 \mathrm{~mm}$, ML $1.0 \mathrm{~mm}$ ). Following a 1 week recovery period, animals were tethered to an electrode harness (Plastics One, 363) and slip-ring commutator (Plastics One, SL6C) permitting free movement for 24/7 video/ECoG monitoring throughout the duration of the experiment. Spontaneous ECoG signals were amplified $(\times 10000)$ and digitized at $500 \mathrm{~Hz}$. Spontaneous ECoG and video were stored for subsequent SWD event detection and related behavioral analysis. After mortality/attrition, a total of 37 FPI rats underwent subsequent (beginning 2 weeks postinjury) continuous video/ECoG (Fig. $1 E$ ) to establish a temporal profile of SWD events over time.

Semiautomated SWD detection and quantification. Automated detection was only used to quantify SWD events, and did not replace visual examination of all video/ECoG for seizure and epileptiform discharge detection. ECoG data were analyzed in $1 \mathrm{~s}$ segments, across $48 \mathrm{~h}$ time epochs per rat at 1, 3, 6, 9, and 12 months of age (Fig. $1 F$ ). Recording was biased toward rats $\geq 6$ months of age according to previous reports of greater incidence of SWD in this age group (Aldinio et al., 1985; Kaplan, 1985; Kleinlogel, 1985; Buzsáki et al., 1990a,b; Kelly et al., 2001; Khar- 
lamov et al., 2003; Pearce et al., 2014). Approximately 20 segments containing SWD were visually selected to establish a template for each rat. Auto-covariance functions were computed for identified segments to capture the amplitude, frequency, and waveform morphology of the SWD. Covariance functions for SWD trials and similar functions for segments containing representative noise were used to train a support vector machine (Orrù et al., 2012) to automatically discriminate between SWD and noise throughout $48 \mathrm{~h}$ of data for each rat at each age recorded for that rat. All detected SWD events for a given $48 \mathrm{~h}$ period were visually examined and artifacts deleted before the number and durations of SWD events were extracted for statistical analysis. In rats where all four electrodes were viable for comparison, recordings of 10 SWD epochs per rat were also examined to assess asynchronous versus synchronous onset. If SWD began in one electrode channel at least $100 \mathrm{~ms}$ before activity could be detected in other channels, it was considered an asynchronous onset. Synchronous onsets were characterized by no detectable delay of SWD between the four recording electrodes. Isolated onsets were defined as SWD bursts that never spread beyond a single electrode. Behavior during automatically detected SWD was assessed for representative $48 \mathrm{~h}$ periods with timelocked video. Rats were also visually observed during SWD to detect subtle behaviors (i.e., vibrissa and jaw movements).

Convulsive seizure detection and quantification. Visual detection of potential convulsive seizures was performed using custom software. All video/ECoG recorded 24/7 for a given rat was displayed in $30 \mathrm{~min}$ blocks on high-resolution monitors. For an event to qualify as a convulsive seizure, ECoG activity had to be differentiated from background noise by the appearance of large-amplitude (at least three times baseline), highfrequency (minimum of $5 \mathrm{~Hz}$ ) activity, with progression of the spike frequency that lasted for a minimum of $20 \mathrm{~s}$. With this electrographic identification, video data would then determine seizure intensity and to confirm ECoG seizure activity versus potential animal-generated noise, such as eating and grooming, and be rated according to Racine's behavioral scale (Racine, 1972), recently modified to rate the intensity of posttraumatic seizures (D’Ambrosio et al., 2004). ECoG was simultaneously examined for putative epileptiform spikes distinct from either convulsive seizures or SWD.

\section{Results \\ FPI injury}

By 5 months postinjury, FPI typically induced damage at the locus of the craniotomy beginning at the level of the dorsal hippocampus. Contralateral brain structures appeared to be morphologically preserved, although some ventricular enlargement could be seen in FPI-treated rats contralateral to injury. Just caudal to the craniotomy (Fig. 1D; "ipsi"), FPI induced marked structural damage, cortical atrophy, deformation and atrophy of the hippocampus, and ventricular enlargement.

\section{Appearance and incidence of SWD events}

Figure 2 shows a 20 min epoch of ECoG recorded from a control rat (9 months). During this time period, the animal displayed a characteristic range of SWD durations, from long (several minutes; Fig. 2A, red traces) to short (several seconds; Fig. 2B, blue traces). Frequent and very brief SWD bursts (i.e., "larval," $<1$ s; Fig. $2 C$, blue traces at bottom), comprised of only a few spikes, also typified SWD recordings. In Figure 3, exemplary traces from Figure $2(A-C)$ are replotted at different timescales. SWD events, such as those depicted here, were typically characterized by an abrupt ( $<1 \mathrm{~s}$ ) onset and termination (Fig. $3 A, B$, arrows), lack of postevent amplitude suppression, and spindle-like variations in amplitude throughout the event. SWD frequency $(\sim 8 \mathrm{~Hz}$ in this example) and morphology appeared stable through the entire event duration (Fig. 3A). There were also no clear differences in SWD characteristics between long and short events (Fig. $3 A$ and $B$, respectively). Larval SWDs (Fig. $3 C$ ) were typically reduced in amplitude but displayed a similar waveform morphology to longer epochs.

SWD incidence rate was indistinguishable between FPI and control animals $F_{(1,9)}=0.321, p=0.587$, across all recording time-points. The incidence rate ranged from $66.7-100 \%$ at the 1 and 3 month time points, and from $90-100 \%$ at the 6 month, 9 month, and 1 year time points. As noted below, although the incidence of SWD was high even at 1-3 months, the number and duration of events was far lower than at later time points.

\section{Pattern recognition of SWD events}

Figure 4 shows a $6 \mathrm{~s}$ SWD event (Fig. $4 A$, red) detected in an uninjured 12-month-old rat. For automated event detection, data were analyzed in successive $1 \mathrm{~s}$ blocks. The auto-covariance function for each block (Fig. 4B, C, dark trace) captured both the amplitude and morphology of SWD (Fig. 4C, light trace) with clear spike and wave components (Fig. 4C; "S" and "W," respectively). A quadratic kernel was trained on the auto-covariance functions of 20-30 visually identified $1 \mathrm{~s}$ blocks of SWD for each rat at each age, and then used to detect subsequent SWD for that animal.

\section{Spatiotemporal features of SWD events}

A total of 470 and 510 SWD events in the FPI and control rats, respectively, were examined for isolated, asynchronous, or synchronous onset. In no animals did SWD in the two parietal leads precede the frontal electrodes. While right versus left asynchronous onsets in the frontal leads were observed, a majority of SWD events in FPI and control animals began synchronously $(79 \%$ and 90\%, respectively). In FPI rats, 13\% of SWD showed asynchronous onset starting in the right frontal electrode at the site of injury, compared with $6 \%$ starting in the left hemisphere. However, there was also a right hemisphere preference (7\%) compared with the left hemisphere (2\%) for SWD onset in the control animals. We recorded isolated (1 electrode only) SWD in only a very small number of events for either FPI or control rats $(2 \%$ and $1 \%$, respectively). A one-way ANOVA conducted to compare the effect of injury group (FPI-injured or uninjured controls) showed no significant group effects on synchronous $\left(F_{(1,96)}=\right.$ $1.39, p=0.241)$, left hemisphere asynchronous $\left(F_{(1,96)}=1.46\right.$, $p=0.229)$, right hemisphere asynchronous $\left(F_{(1,96)}=0.00, p=\right.$ $0.997)$, or isolated SWD onsets $\left(F_{(1,96)}=1.88, p=0.174\right)$.

\section{Behavioral features of SWD events}

When time-locked video was examined, SWD events detected in both uninjured and injured rats were associated with inactivity or interruption of ongoing movement. Real-time visual examination of a subset of control and FPI rats revealed that SWD were often accompanied by vibrissa extension and slight vibrational tremor, similar to previously described " $\alpha$-tremor" in normal Long-Evans rats (Semba and Komisaruk, 1984), and frequently terminated by bruxing movements of the incisors that were sometimes sufficiently intense to produce eye "boggling" (rapid movement of the eye in and out of the socket due to flexing of the masseter muscle). No events exceeding a seizure intensity score of 2 were observed in either FPI or control rats.

\section{SWD counts and lengths as a function of age and injury}

Figure 5 exemplifies SWD in an uninjured rat recorded across 1-12 months of age. One second samples shown here typify SWD in the majority of normal control rats across the recording period (Fig. 5A). SWD were fully developed at 12 months with a clear spike and wave morphology. The number and duration of SWD 


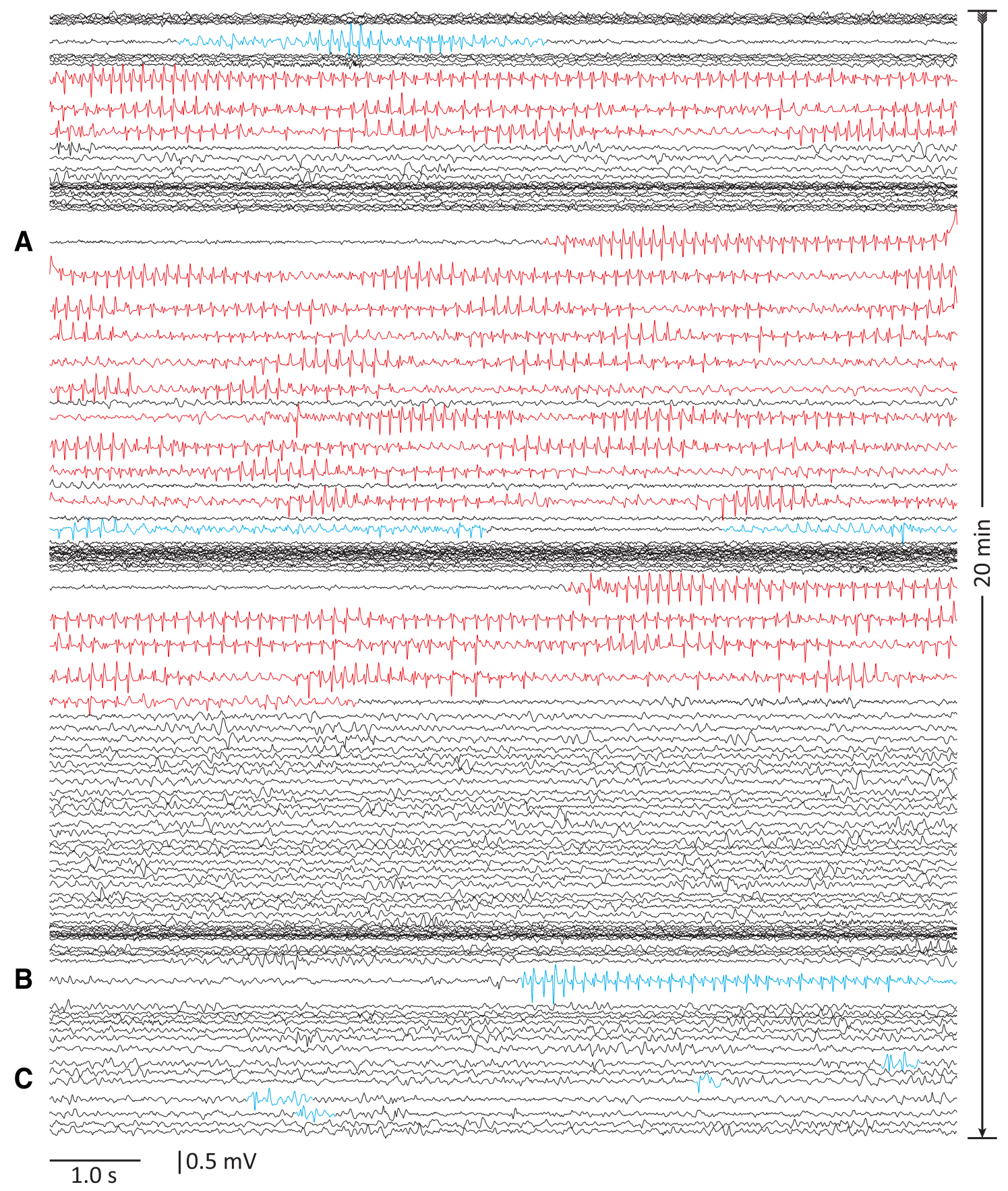

Figure 2. Range of SWD event lengths in a 9-month old control rat. $A$, SWD epochs lasting tens of seconds (red) were rare except in some older animals. $\boldsymbol{B}$, More typical were short SWD bursts of several seconds (blue) and also larval SWD $(C$ often less than a second in length and comprised of only several spikes. Raster plot is a single channel of ECOG plotted as successive $10 \mathrm{~s}$ traces progressing from top to bottom over $20 \mathrm{~min}$ and spaced proportional to amplitude.

events increased with age, but short bursts of larval SWD could be detected at all ages. Despite age-related increases in the number and duration of events, the morphology and frequency, best visualized in the averaged SWD (Fig. 5B) and auto-covariance function (Fig. 5C), appeared similar even when comparisons were made between 1 and 12 month records (Fig. 5; 12 month, light and dark traces, respectively).

The number $(p=0.099)$ and duration $(p=0.132)$ of SWDs did not differ between surgically naive and sham controls, so these groups were combined for the overall analyses. Age-related increases in the number and duration of SWD events are summarized in the grouped control and FPI rats (Fig. 6A,B). A two- way ANOVA was conducted to examine the effect of age (1-12 months) and injury group on the number of SWD events. There was no significant interaction between the effects of age and injury on the number of SWD events (Fig. 6A) for any time point postinjury $\left(F_{(11,356)}=0.600, p=0.700\right)$. There was a main effect found for age, with the total number of SWD events significantly increasing with age $\left(F_{(4,356)}=2.951, p=0.020\right)$. Post hoc comparisons showed that the older (9-12 month) FPI and control rats displayed more SWD events than the younger rats, which was statistically higher at both the 9 month $(p<0.01)$ and 1 year $(p<$ 0.01 ) time points. However, there was not a significant main effect for injury group $\left(F_{(2,356)}=0.338, p=0.713\right)$, indicating no 

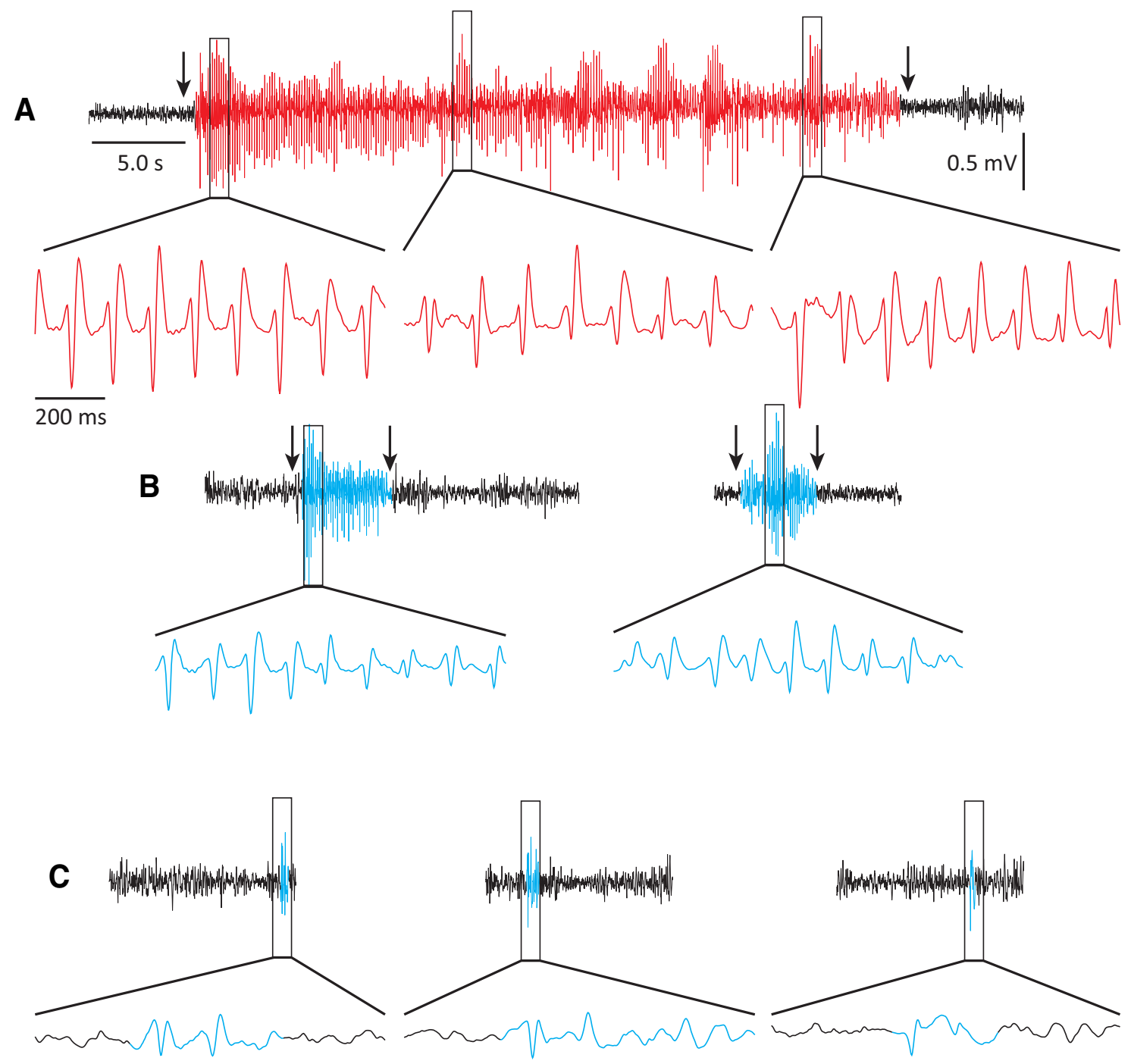

Figure 3. Same data as Figure 2 plotted at compressed and expanded time scales. $A$, Long ( $37 \mathrm{~s})$ SWD epoch begins and ends abruptly ( $<1$ s; arrows). SWD amplitude waxes and wanes over periods of seconds. SWDs are also characterized by no suppression at the end of an epoch. Expansion of $1 \mathrm{~s} \mathrm{samples} \mathrm{taken} \mathrm{from} \mathrm{the} \mathrm{beginning,} \mathrm{middle,} \mathrm{and} \mathrm{end} \mathrm{of} \mathrm{the} \mathrm{epoch} \mathrm{look} \mathrm{similar} \mathrm{in} \mathrm{waveform}$ morphology and frequency. $\boldsymbol{B}$, All characteristics of SWD from infrequent long bursts are similar to the more common shorter bursts. $\boldsymbol{C}$, Larval SWD are also frequent and typically comprised of only several spikes of similar waveform to longer bursts.

difference in the number of SWD events between FPI-injured and uninjured control rats.

A two-way ANOVA examining the effect of age and injury on the duration of SWD events also revealed no significant interaction (Fig. $\left.6 B ; F_{(11,356)}=1.259, p=0.281\right)$. A significant main effect was found for age $\left(F_{(4,356)}=7.189, p=0.000\right)$, reflecting significantly longer SWD duration as a function of age, across both groups. In both FPI and control groups, SWD duration was significantly longer at the 6 month $(p<0.05)$, 9-month $(p<$ $0.05)$ and 1 year $(p<0.05)$ time points. As with the number of SWD events, there was no main effect for injury group and SWD duration across any time point postinjury $\left(F_{(2,356)}=2.041, p=\right.$ $0.131)$.

Characterization of the SWD events by burst length in uninjured controls (Fig. 6C) showed that the number of SWD bursts declined with increasing length. SWD burst length parameters for FPI-injured rats (Fig. 6D) followed very similar age-related patterns and were not significantly different from the uninjured controls $\left(F_{(39,2379)}=1.491, p=0.078\right)$. There was not a significant main effect found for injury group $\left(F_{(39,2379)}=2.563, p=\right.$
0.110). There was a significant main effect found for burst length $\left(F_{(39,2379)}=123.881, p=0.000\right)$, revealing that there were significantly more $1-3$ s SWD events than $4-20$ s events $(p<0.010)$.

\section{SWD frequency, morphology, and sensory interruption as a function of injury}

SWD frequency (referring to spike repetition rate, not frequency of bursts) was consistently in the range of $7-9 \mathrm{~Hz}$ and did not differ between uninjured $(7.7 \mathrm{~Hz} \pm 0.4)$ and injured $(7.9 \mathrm{~Hz} \pm$ 0.3 ) animals (Fig. 7A). SWD morphology was also qualitatively similar between groups (Fig. $7 B$ ). In a final comparison, we used automated SWD detection to trigger an auditory stimulus $(\sim 65$ $\mathrm{dB}$ SPL; $20 \mathrm{~cm}$ distance) during ongoing SWD events in a subset of 9 control and 12 FPI rats (Fig. 8). It has been noted in other studies that, unlike seizures, normal SWD may be interrupted by sensory stimulation and arousal (Robinson and Gilmore, 1980; Semba et al., 1980; Vergnes et al., 1982; Kaplan, 1985; Buzsáki et al., 1990b; Wiest and Nicolelis, 2003; Shaw, 2004; Pearce et al., 2014). Similar to these previous reports, a click had the effect of rapidly aborting ongoing SWD in our control rats (single trial 


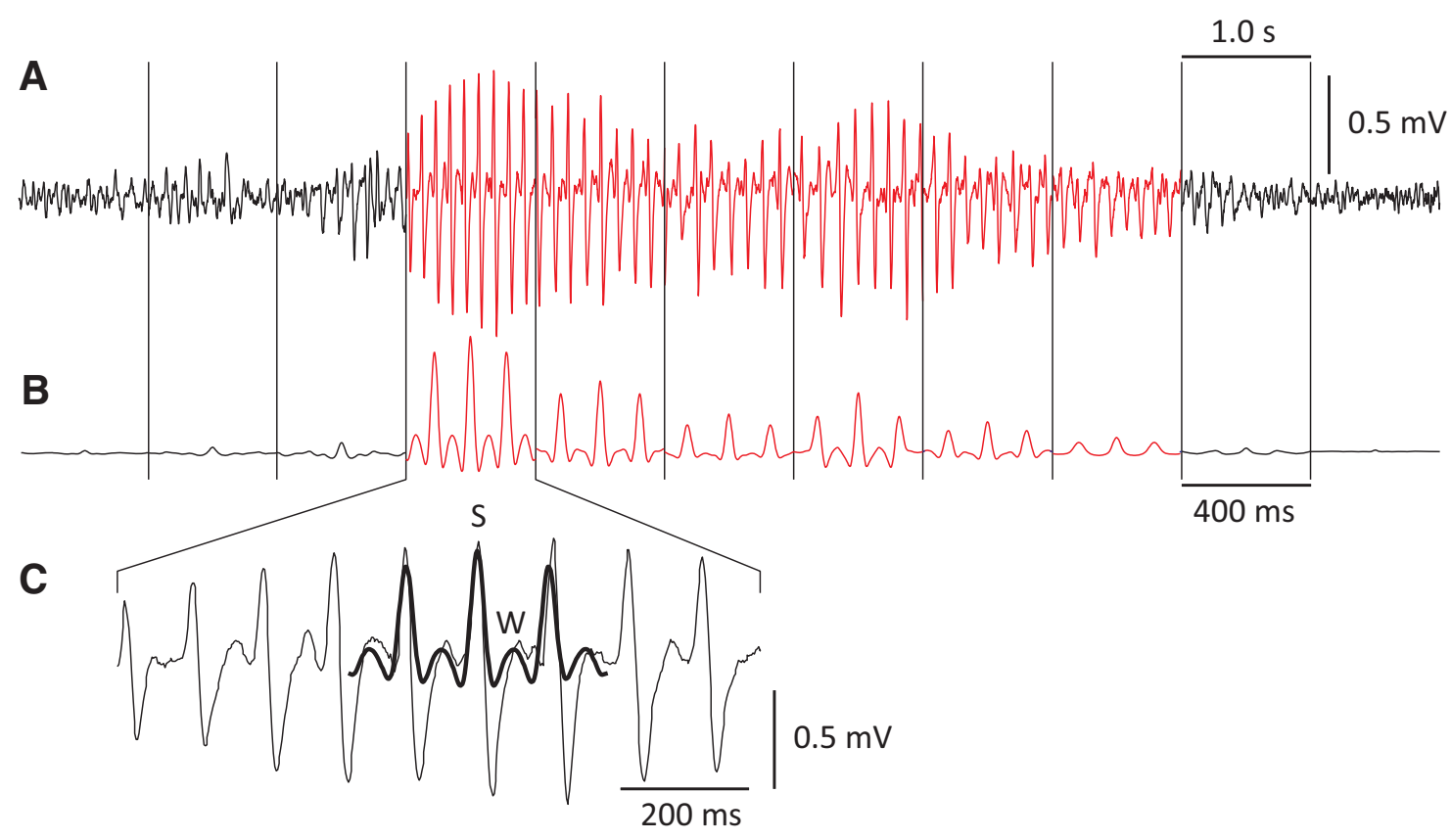

Figure 4. SWD and segmented auto-covariance function for pattern recognition. $A$, Six second burst of spontaneous SWD detected by pattern recognition (red) recorded from parietal cortex of normal 12-month-old Sprague-Dawley control rat. The SWD burst is analyzed in $1 \mathrm{~s} \mathrm{segments.} \boldsymbol{B}$. Auto-covariance functions of successive $1 \mathrm{~s}$ bursts computed with lags of $\pm 200 \mathrm{~ms}$ capture the periodicity, wave-shape, and amplitude of the SWD segment as features for pattern recognition. Typical of SWD events, the amplitude of the covariance function waxes and wanes but the frequency and morphology remain steady from the beginning to the end. C, Enlarged $1 \mathrm{~s}$ segment of SWD (light trace) with scaled and superimposed auto-covariance function (dark trace) highlighting the spike (S) and wave (W) components.

example shown in Fig. $8 A)$. Figures $8 B, C$, shows averaged spectrograms $(n=10$ trials each) of click-evoked SWD suppression for two control and two FPI rats, respectively. Note also in these spectrograms, the stereotyped harmonic spectral bands for SWD marked with white lines at the fundamental frequency $(7-9 \mathrm{~Hz})$ and the first higher harmonic $(14-18 \mathrm{~Hz})$. The percentage of click-evoked SWD suppression was calculated for all rats by comparing the ratio of total root mean squared (RMS) power for $2 \mathrm{~s}$ before and after the click. The average suppression was $89.3 \pm$ $0.48 \%$ and $90.5 \pm 0.55 \%$ for the control and FPI, respectively (Fig. $8 D$ ), and did not significantly differ between the groups $(p=0.16)$.

\section{Convulsive seizures}

None of our injured or uninjured rats developed convulsive seizures based on criteria used to identify these events in poststatus epilepticus models of epilepsy, even when recorded to 12 months of age. We also failed to observe epileptiform discharges (spikes) in our injured or control rats.

\section{Summary of results}

The key results from these experiments are as follows: (1) The SWD episodes from FPI rats had waveforms, durations, and frequencies that were virtually identical to previous reports on a highly similar FPI model of PTE (D'Ambrosio et al., 2004, 2005; Curia et al., 2011). (2) Unlike previous reports, however, the SWDs were equally prominent in sham-surgery and uninjured control rats, with close similarities in both electrographic and behavioral features. (3) In both FPI and control rats, the SWDs were generally only a few seconds in duration, but could persist for tens of seconds, although these longer duration events were comparatively rare and only seen in older animals (including controls). (4) The onset of SWDs was usually synchronous across the cortical recording electrodes; however, SWD onset could oc-

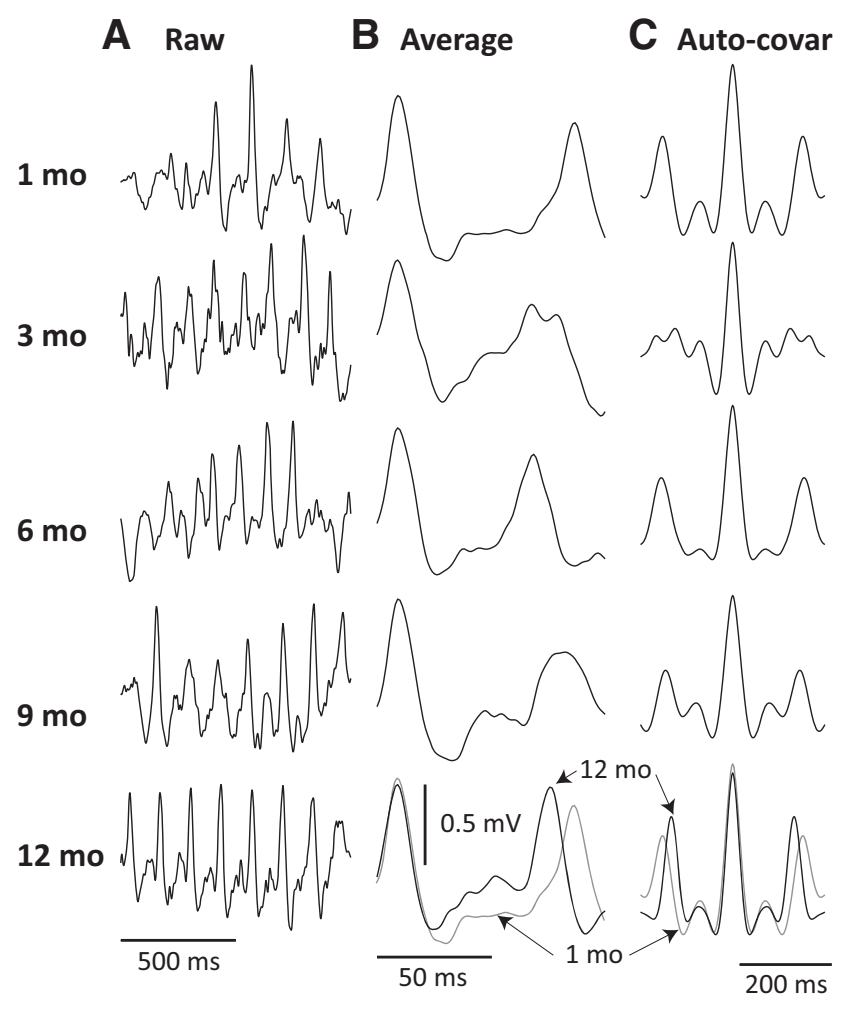

Figure 5. Evolution of SWD in an aging control rat. $A$, Raw (unaveraged) SWDs at 1 month are typically brief $(<2 s)$ and occur infrequently. Both the duration and frequency of occurrence increase with age but the waveform morphology and frequency remain stable over the 12 month time-span. The stability of frequency and SWD waveform over the 12 month time-span are reflected in both the averaged SWD $(n=3-5 ; \boldsymbol{B})$ and auto-covariance functions $(\boldsymbol{C})$ computed from the $1 \mathrm{~s}$ samples shown in $\boldsymbol{A}$, with little difference at 12 months (dark traces) compared to 1 month (light traces). 
A

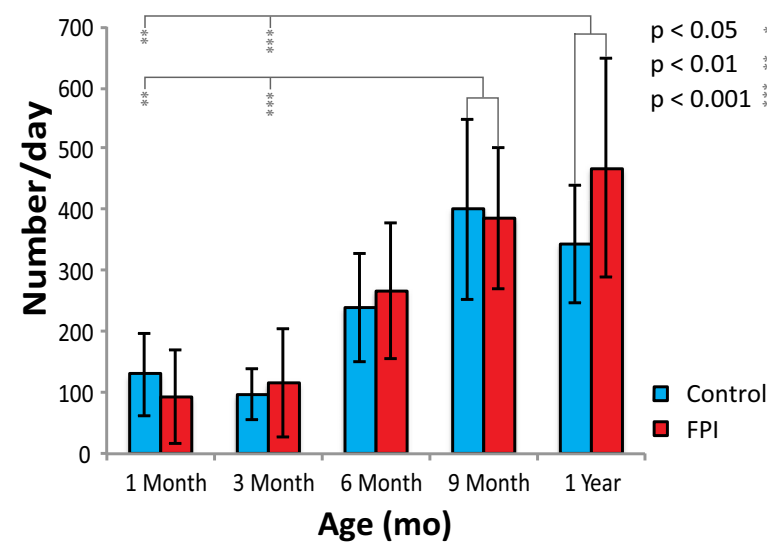

C

Control

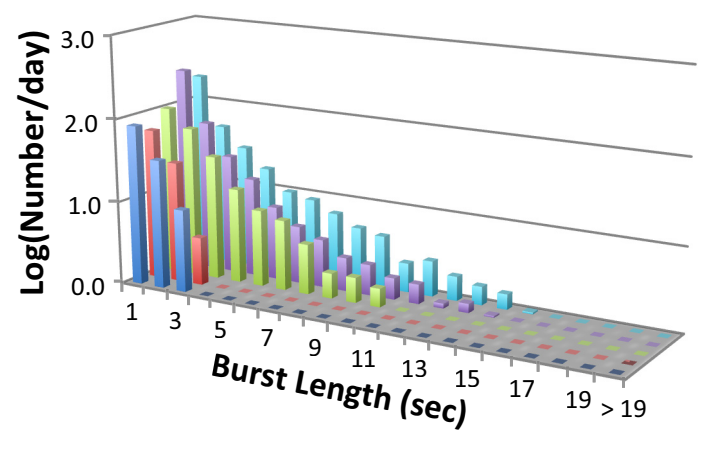

B

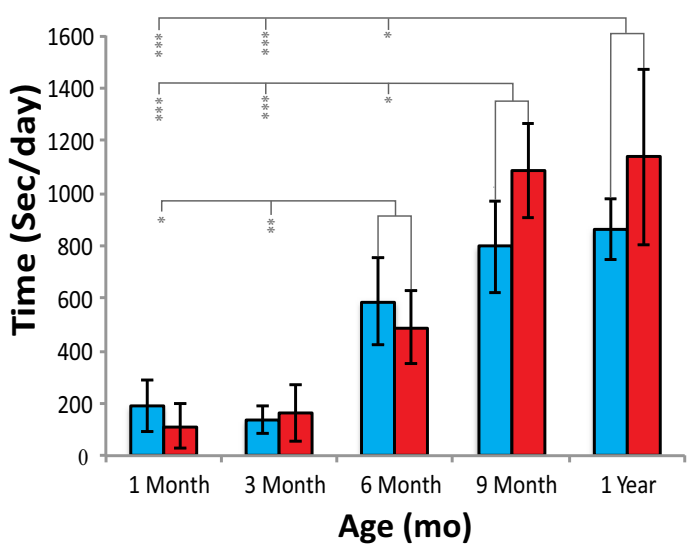

FPI

Figure 6. Comparison of SWD events, time, and burst durations in control versus FPI rats. $A$, There were no significant differences found in the number of SWD events between FPI and control rats; however, older rats ( 9 months and 1 year) had significantly more SWD events. $\boldsymbol{B}$, The SWD duration was higher in older rats, significantly increased across 6 months, 9 months, and 1 year. As with the number of SWD events, no statistical differences were detected between FPI and control rats. $\boldsymbol{C}, \boldsymbol{D}$, Young (1 and 3 month) control (C) and FPI (D) rats showed a predominance of $1-3 \mathrm{~s}$ SWD bursts, with negligible bursts of longer duration. The total number of bursts was lowest in young animals. Bursts counts in both groups of rats increased with age and peaked at 9 months to 1 year, with corresponding age related increases in longer duration $(>6 \mathrm{~s})$ bursts. Data represent mean \pm SD.

cur earlier on one particular electrode, but the difference in apparent onset was brief (hundreds of milliseconds) and not consistently related to the site of injury. (5) A variety of sensory stimuli, such as a "click," consistently blocked the SWDs in both groups. (6) The SWDs appeared remarkably similar to events previously reported by others in several strains of uninjured inbred and outbred rats. (7) Convulsive seizures, characteristic of other animal models of acquired epilepsy arising from induced status epilepticus or perinatal hypoxia-ischemia, were never observed.

\section{Discussion}

In human epilepsy, nonconvulsive seizures have classically been divided into two general types: complex partial (i.e., focal dyscognitive; Berg et al., 2010) and absence seizures. These seizure types have distinctly different etiologies and electrographic/behavioral properties, but each can be misinterpreted for the other.

\section{SWD after FPI do not reflect complex partial seizures}

PTE and other forms of acquired epilepsy are characterized by simple (i.e., motor or sensory) and complex (loss of consciousness) partial (focal) seizures that: (1) initially have a seizure onset zone near the site of the injury, and (2) have prolonged durations (minutes), particularly when they spread to other areas. Although formal plots of the distribution of seizure durations are lacking, abundant clinical data (Theodore et al., 1983, 1994; Williamson et al., 1985; Devinsky et al., 1988; Jenssen et al., 2006; Afra et al., 2008; Kim et al., 2011) have characterized simple and complex partial seizures (CPSs) in humans with PTE and other forms of acquired epilepsy as having minimum durations of $10-20 \mathrm{~s}$, but often lasting minutes. Thus, the seizure durations of CPSs are markedly different from the distribution of durations observed here (Fig. 6) and are nearly an order of magnitude longer than those most of the events described for the FPI model (Eastman et al., 2015).

Other characteristics of SWDs recorded here are also at odds with those of CPSs in humans and with the nonconvulsive seizures that can occur in kainate and pilocarpine models of acquired epilepsy in rats. The seizures in acquired human epilepsy and in these other models typically: (1) increase intensity over many seconds at onset, (2) undergo an evolution in activity over time during the seizure, and (3) show a postictal suppression of ECoG activity-unlike the: (1) sudden onset, (2) relatively homogeneous pattern, and (3) abrupt termination typical of SWDs. Finally, SWDs can be easily terminated with mild sensory stimulation, a phenomenon not observed with CPSs.

\section{SWD after FPI may reflect absence seizures}

Absence epilepsy, a form of childhood genetic epilepsy, involves absence seizures that are shorter than CPSs (5-15 s, but can range 
A

SWD Frequency

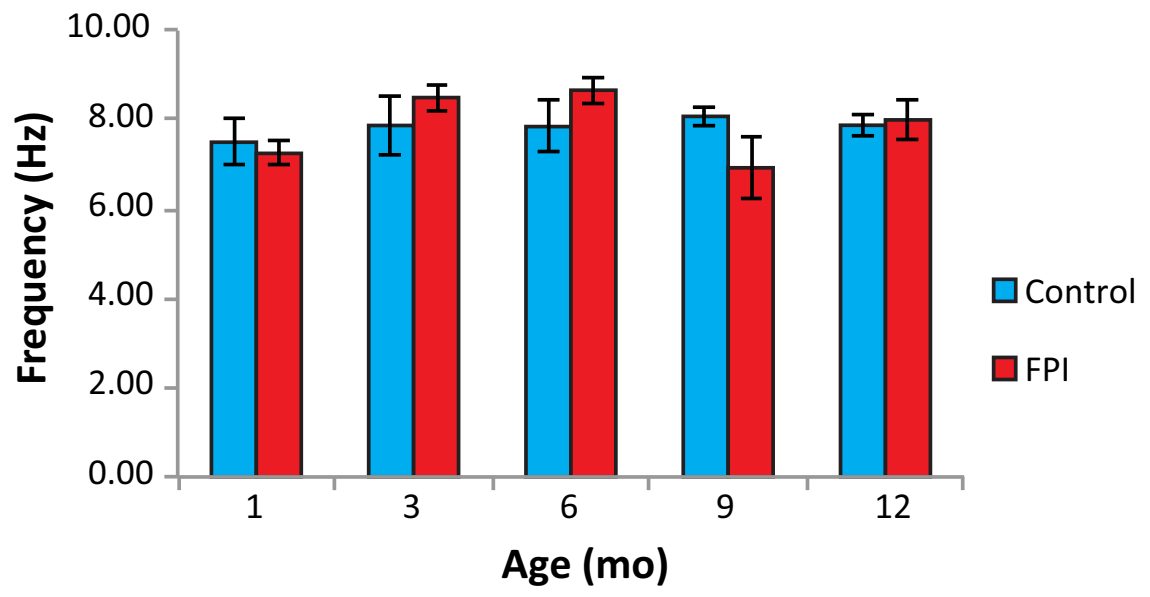

B

\section{Control}

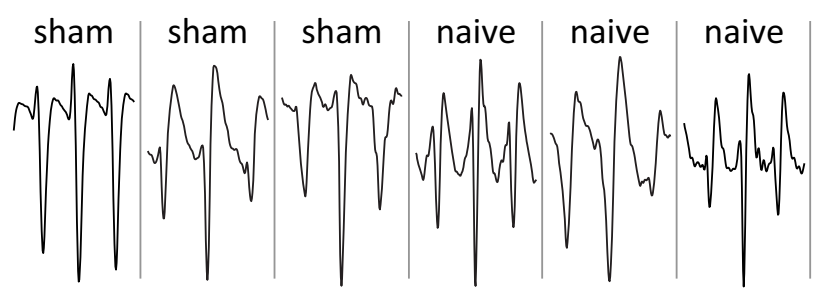

\section{FPI}

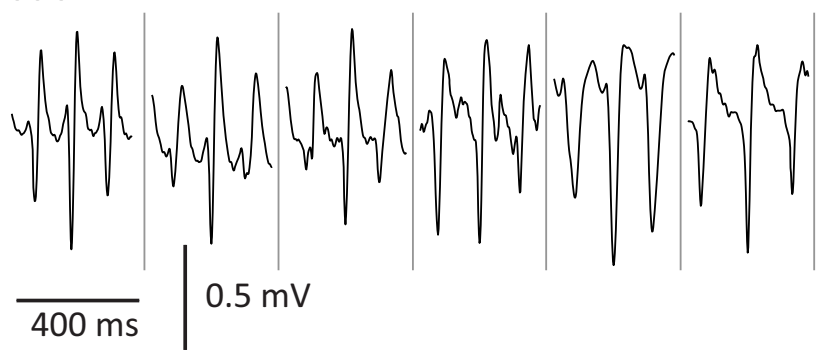

Figure 7. SWD frequency (repetition rate of spikes) and morphology for control versus FPI rats. $A$, Spike frequency for both control and brain-injured rats across 12 months of age. $\boldsymbol{B}$, Top, Exemplary averaged $(n=3-5)$ fully developed SWD at $9-12$ months age for rats receiving sham surgery at 1 month ("sham") and older naive rats (implanted at 9-12 months). No morphological differences could be discernedforthesetwo groups. $\boldsymbol{B}$, Bottom, Similarto the top butshowing averaged SWD for 9-to 12-month-old FPI rats. Datarepresentmean \pm SD.

Long-Evans (Shaw, 2004; Huang et al., 2012) and Sprague-Dawley strains (Wiest and Nicolelis, 2003). The distinct waveform of SWDs, their rapid onset and termination, and their lack of postictal suppression are defining characteristics of absence seizures in these animals but not of CPSs. Finally, it has been shown that SWDs in uninjured outbred SpragueDawley rats can be abolished by ethosuximide (a human anti-absence drug; Pearce et al., 2014), strengthening the connection with absence seizures.

As a form of primary generalized epilepsy, absence seizures can have synchronous onsets at all electrode sites, similar to the SWDs observed here. Occasionally, SWD activity appeared to begin at one electrode, but this was rare and was independent of injury location. Although previous studies of the FPI model have suggested that focal onsets may be a key feature distinguishing postinjury subconvulsive events from absence seizures (D'Ambrosio et al., 2005), there is a lack of quantitative control data illustrating this distinction. In addition, absence seizures in inbred rats often display asynchronous onsets with the leading cortical focus in rostral electrode sites near the perioral region of sensorimotor cortex (Meeren et al., 2002), leading to the current "cortical focus" theory of absence epilepsy (Meeren et al., 2005). Signal analytic methods have also demonstrated early focal changes in thalamocortical interactions demonstrating a perioral cortical hot-spot of hyperexcitability triggered seconds in advance of SWD (Lüttjohann and van Luijtelaar, 2015).

\section{Progression of SWDs with age}

An important concept in acquired epilepsy is that the frequency and severity of spontaneous recurrent seizures often increase with time after the injury. Using

from 1 to tens of seconds). Absence seizures are more frequent than CPSs; a frequency of many seizures per day is common, and occasionally dozens per hour occur. CPSs, however, are rarely more frequent than a few per day, and these would generally be considered "clusters." SWDs recorded here from FPI and control animals occurred many times per hour and were commonly only a few seconds in duration, which are properties virtually identical to those classically described for absence seizures (Sato, 1983; Pearl and Holmes, 2008), also interpreted as "nonconvulsive" seizures in a recent FPI study but observed regularly in control, sham, and injured rats (Campbell et al., 2014). Other features of SWDs recorded in our FPI and control rats had much closer similarity to absence seizures than CPSs. For example, the rhythmic nature of SWD events in the range of $5-10 \mathrm{~Hz}$, slightly faster but similar to absence seizures in humans, has been amply described in several models of absence epilepsy in inbred (Danober et al., 1998) and as normal events in outbred rats, such as the both nonconvulsive and convulsive seizures with durations comparable with those observed in human CPSs, a progressive increase in seizure frequency has been demonstrated in models of status epilepticus (Aldinio et al., 1985; Lothman and Bertram, 1993; Bertram and Cornett, 1994; Nissinen et al., 2000; Kelly et al., 2001; Kharlamov et al., 2003; Williams et al., 2009), and also more recently in a model of perinatal hypoxia-ischemia (Kadam et al., 2010). Previous studies with FPI (Eastman et al., 2015), based on relatively brief SWD-like events occurring at a frequency of many per hour, have also reported a progressive increase in frequency after brain insult. Although this observation would appear to be evidence of acquired epilepsy in the FPI model, our data showing increases in frequency and duration of SWD in control rats puts this interpretation in question.

Absence epilepsy is most prominent in childhood. However, in accepted inbred rat models of absence, as well as the present data, SWD events are rare in younger animals and become more 
SWD Interruption

A

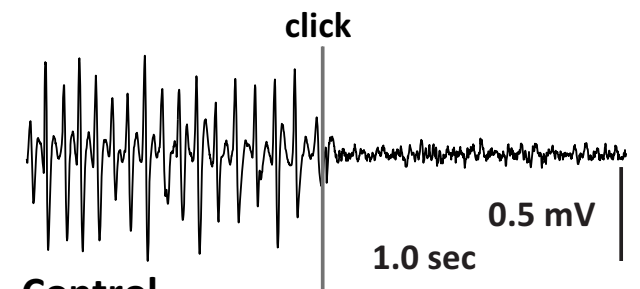

B
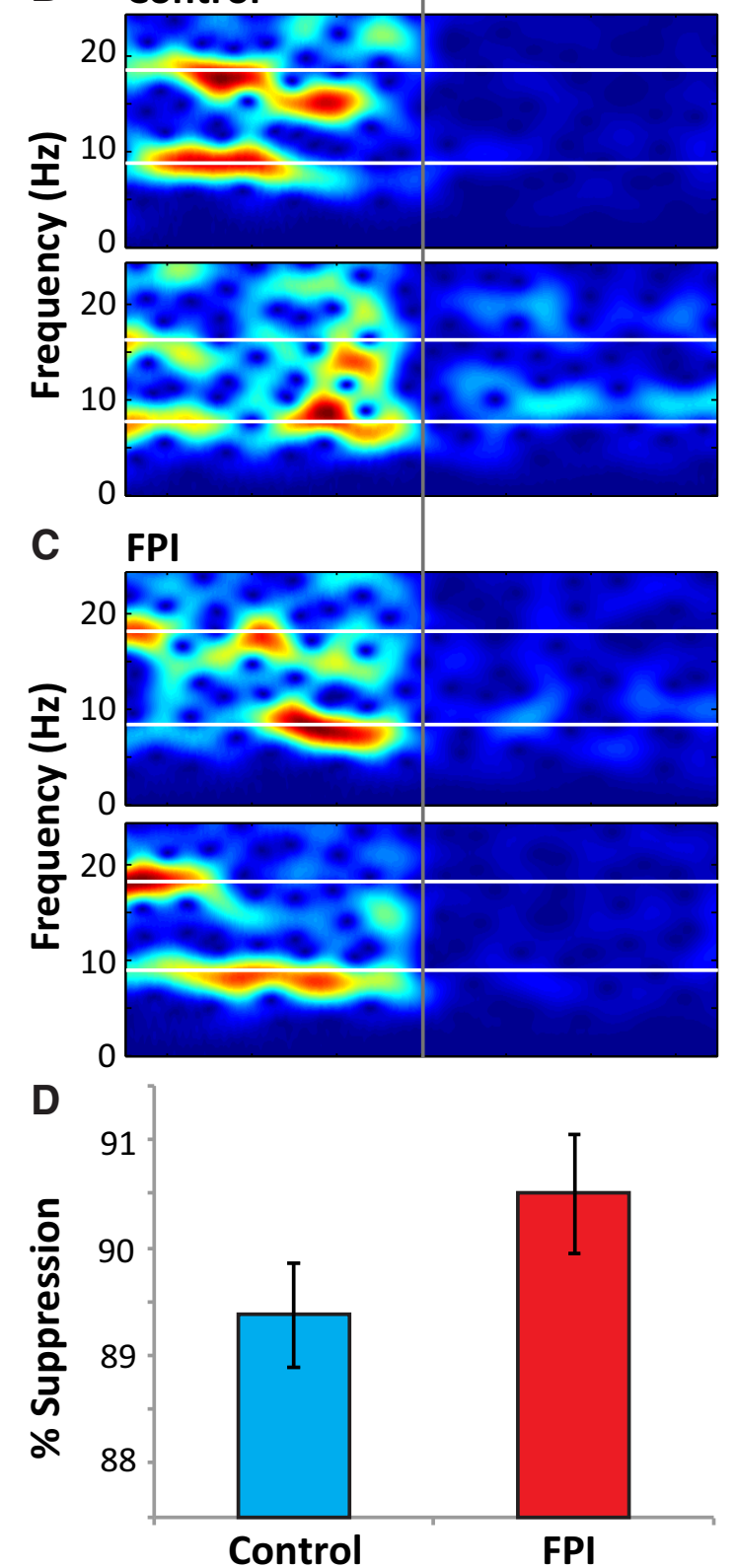

Figure 8. Interruption of ongoing SWD events with acoustic stimulus. $\boldsymbol{A}$, Single raw trace of SWD recorded from a control rat, immediately aborted by click stimulus. $\boldsymbol{B}, \mathrm{Com}-$ puted spectrogram permitted averaging $(n=10)$ the SWD interruption across multiple trials for two exemplary control rats. White horizontal lines indicate the fundamental frequency (lower line) and first harmonic (upper line). $\boldsymbol{C}$, Same as $\boldsymbol{B}$ but averaged spectrograms for two FPI rats. Ages of both control and FPI rats in these examples were 12 months. $D$, Percentage change of RMS power prestimulus and poststimulus for the control (blue; $n=9$ ) and FPI (red; $n=12$ ) groups. Data represent mean \pm SD. frequent and prolonged as animals become older (Coenen and van Luijtelaar, 1987). Thus, the analogy with absence epilepsy in humans is poor in regard to life history of the disease. This has been noted as one of several weaknesses of absence epilepsy models (Kaplan, 1985), but does not suggest similarity to CPS of acquired epilepsy, because age-related increases in SWD are common in outbred and inbred rats.

Other brain-injury models of acquired epilepsy in the rat Our failure to obtain CPS was surprising in light of other reports (Kharatishvili et al., 2006; Bolkvadze and Pitkänen, 2012; Shultz et al., 2013; Campbell et al., 2014; D. Poulsen, personal communication). This may indicate a marked sensitivity of the model to experimental parameters. We relied on rostral parasagittal FPI reported by others to be highly successful (D'Ambrosio et al., 2004, 2005; Curia et al., 2011). Like these studies, FPI resulted in a $10 \%$ mortality rate with severe impact pressures and posttrauma apnea $>15 \mathrm{~s}$ that required resuscitation. Yet, these outcome measures alone may not indicate sufficient cortical and subcortical damage for epileptogenesis. Recent studies suggest caudal and lateral impact locations with a wider $(5 \mathrm{~mm})$ craniotomy may be more effective in yielding convulsive seizures and that the impact must be sufficient to produce damage to entorhinal cortex and hippocampus, as well as resulting in mortality rates on the order of 32\% (Kharatishvili and Pitkänen, 2010). Only these examples seem appropriate as models of bona fide acquired epilepsy, producing CPSs in $50 \%$ of rats monitored continuously for 12 months. If the rostral parasagittal percussion model were equally effective in producing CPSs instead of SWD, we should have had at least five rats with convulsive seizures in the FPI group monitored for 1 year. Instead, we recorded no CPS or epileptiform discharges in any of our rats.

Chronic recurrent seizures with the characteristics of acquired epilepsy have also been seen after controlled cortical impact, another possible model of PTE (Statler et al., 2009; Bolkvadze and Pitkänen, 2012). In a perinatal hypoxia-ischemia model (Kadam et al., 2010) and in a new model of penetrating brain injury (Kendirli et al., 2014), both nonconvulsive and convulsive seizures have been observed. Thus, several other animal models of severe brain injury, including TBI and stroke, and not limited to status epilepticus, have shown nonconvulsive and convulsive seizures that appear substantially different from the SWDs observed here, and different from the SWD events previously attributed to epilepsy from FPI.

\section{Conclusions}

We conclude that the SWDs recorded here, in both FPI and control rats, are a model of absence seizures in humans. The fact that SWDs in normal Sprague-Dawley rats may be genetically enhanced in inbred species further strengthens the connection to human genetic epilepsy. Just like mild sensory stimulation, observed here to abort SWD, would not affect actual CPSs, methods for epilepsy therapy based on control of post-traumatic SWDs (D'Ambrosio and Miller, 2010; Eastman et al., 2015) are unlikely to impact human CPSs. All features of SWD events in the present results are remarkably similar to reports of models of PTE based on FPI (D'Ambrosio et al., 2009). The data reported here, combined with previous work (Kelly et al., 2006; Pearce et al., 2014), raises serious questions about the validity of the FPI model of acquired epilepsy. These studies suggest that a major reassessment of "What is a seizure?" in the context of acquired epilepsy, and thus "What defines a model of acquired epilepsy?," is needed. 


\section{References}

Afra P, Jouny CC, Bergey GK (2008) Duration of complex partial seizures: an intracranial EEG study. Epilepsia 49:677-684. CrossRef Medline

Agrawal A, Timothy J, Pandit L, Manju M (2006) Post-traumatic epilepsy: an overview. Clin Neurol Neurosurg 108:433-439. CrossRef Medline

Aldinio C, Aporti F, Calderini G, Mazzari S, Zanotti A, Toffano G (1985) Experimental models of aging and quinolinic acid. Methods Find Exp Clin Pharmacol 7:563-568. Medline

Berg AT, Berkovic SF, Brodie MJ, Buchhalter J, Cross JH, van Emde Boas W, Engel J, French J, Glauser TA, Mathern GW, Moshé SL, Nordli D, Plouin P, Scheffer IE (2010) Revised terminology and concepts for organization of seizures and epilepsies: report of the ILAE commission on classification and terminology, 2005-2009. Epilepsia 51:676-685. CrossRef Medline

Bertram EH, Cornett JF (1994) The evolution of a rat model of chronic spontaneous limbic seizures. Brain Res 661:157-162. CrossRef Medline

Bolkvadze T, Pitkänen A (2012) Development of post-traumatic epilepsy after controlled cortical impact and lateral fluid-percussion-induced brain injury in the mouse. J Neurotrauma 29:789-812. CrossRef Medline

Buzsáki G, Smith A, Berger S, Fisher LJ, Gage FH (1990b) Petit mal epilepsy and parkinsonian tremor: hypothesis of a common pacemaker. Neuroscience 36:1-14. CrossRef Medline

Buzsáki G, Laszlovszky I, Lajtha A, Vadász C (1990a) Spike-and-wave neocortical patterns in rats: genetic and aminergic control. Neuroscience 38:323-333. CrossRef Medline

Campbell JN, Gandhi A, Singh B, Churn SB (2014) Traumatic brain injury causes a tacrolimus-sensitive increase in non-convulsive seizures in a rat model of post-traumatic epilepsy. Int J Neurol Brain Disord 1:1-11. CrossRef Medline

Coenen AM, van Luijtelaar EL (1987) The WAG/Rij rat model for absence epilepsy: age and sex factors. Epilepsy Res 1:297-301. CrossRef Medline

Curia G, Levitt M, Fender JS, Miller JW, Ojemann J, D’ Ambrosio R (2011) Impact of injury location and severity on posttraumatic epilepsy in the rat: role of frontal neocortex. Cereb Cortex 21:1574-1592. CrossRef Medline

D'Ambrosio R, Miller JW (2010) What is an epileptic seizure? Unifying definitions in clinical practice and animal research to develop novel treatments. Epilepsy Currents 10:61-66. CrossRef Medline

D'Ambrosio R, Fairbanks JP, Fender JS, Born DE, Doyle DL, Miller JW (2004) Post-traumatic epilepsy following fluid percussion injury in the rat. Brain 127:304-314. CrossRef Medline

D’Ambrosio R, Fender JS, Fairbanks JP, Simon EA, Born DE, Doyle DL, Miller JW (2005) Progression from frontal-parietal to mesial-temporal epilepsy after fluid percussion injury in the rat. Brain 128:174-188. CrossRef Medline

D’Ambrosio R, Hakimian S, Stewart T, Verley DR, Fender JS, Eastman CL, Sheerin AH, Gupta P, Diaz-Arrastia R, Ojemann J, Miller JW (2009) Functional definition of seizure provides new insight into post-traumatic epileptogenesis. Brain 132:2805-2821. CrossRef Medline

Danober L, Deransart C, Depaulis A, Vergnes M, Marescaux C (1998) Pathophysiological mechanisms of genetic absence epilepsy in the rat. Prog Neurobiol 55:27-57. CrossRef Medline

Devinsky O, Kelley K, Porter RJ, Theodore WH (1988) Clinical and electroencephalographic features of simple partial seizures. Neurology 38:13471352. CrossRef Medline

Dudek FE, Bertram EH (2010) Counterpoint to "What is an epileptic seizure?" By D’Ambrosio and Miller. Epilepsy Curr 10:91-94. CrossRef Medline

Eastman CL, Fender JS, Temkin NR, D'Ambrosio R (2015) Optimized methods for epilepsy therapy development using an etiologically realistic model of focal epilepsy in the rat. Exp Neurol 264:150-162. CrossRef Medline

Engel J (2013) Seizures and epilepsy, Vol 83. Contemporary Neurology Series. New York: Oxford UP.

Frey LC, Hellier J, Unkart C, Lepkin A, Howard A, Hasebroock K, Serkova N, Liang L, Patel M, Soltesz I, Staley K (2009) A novel apparatus for lateral fluid percussion injury in the rat. J Neurosci Methods 177:267-272. CrossRef Medline

Hammond EJ, Villarreal HJ, Wilder BJ (1979) Distinction between normal and epileptic rhythms in rodent sensorimotor cortex. Epilepsia 20:511517. CrossRef Medline

Huang HY, Lee HW, Chen SD, Shaw FZ (2012) Lamotrigine ameliorates seizures and psychiatric comorbidity in a rat model of spontaneous absence epilepsy. Epilepsia 53:2005-2014. CrossRef Medline

Jenssen S, Gracely EJ, Sperling MR (2006) How long do most seizures last? A systematic comparison of seizures recorded in the epilepsy monitoring unit. Epilepsia 47:1499-1503. CrossRef Medline

Kadam SD, White AM, Staley KJ, Dudek FE (2010) Continuous electroencephalographic monitoring with radio-telemetry in a rat model of perinatal hypoxia-ischemia reveals progressive post-stroke epilepsy. J Neurosci 30:404-415. CrossRef Medline

Kaplan BJ (1985) The epileptic nature of rodent electrocortical polyspiking is still unproven. Exp Neurol 88:425-436. CrossRef Medline

Kelly KM, Kharlamov A, Hentosz TM, Kharlamova EA, Williamson JM, Bertram EH 3rd, Kapur J, Armstrong DM (2001) Photothrombotic brain infarction results in seizure activity in aging Fischer 344 and Sprague Dawley rats. Epilepsy Res 47:189-203. CrossRef Medline

Kelly KM, Jukkola PI, Kharlamov EA, Downey KL, McBride JW, Strong R, Aronowski J (2006) Long-term video-EEG recordings following transient unilateral middle cerebral and common carotid artery occlusion in Long-Evans rats. Exp Neurol 201:495-506. CrossRef Medline

Kendirli MT, Rose DT, Bertram EH (2014) A model of posttraumatic epilepsy after penetrating brain injuries: effect of lesion size and metal fragments. Epilepsia 55:1969-1977. CrossRef Medline

Kharatishvili I, Pitkänen A (2010) Association of the severity of cortical damage with the occurrence of spontaneous seizures and hyperexcitability in an animal model of posttraumatic epilepsy. Epilepsy Res 90:47-59. CrossRef Medline

Kharatishvili I, Nissinen JP, McIntosh TK, Pitkänen A (2006) A model of posttraumatic epilepsy induced by lateral fluid-percussion brain injury in rats. Neuroscience 140:685-697. CrossRef Medline

Kharlamov EA, Jukkola PI, Schmitt KL, Kelly KM (2003) Electrobehavioral characteristics of epileptic rats following photothrombotic brain infarction. Epilepsy Res 56:185-203. CrossRef Medline

Kim D, Cho JW, Lee J, Joo EY, Hong SC, Hong SB, Seo DW (2011) Seizure duration determined by subdural electrode recordings in adult patients with intractable focal epilepsy. J Epilepsy Res 1:57-64. CrossRef Medline

Kleinlogel H (1985) Spontaneous EEG paroxysms in the rat: effects of psychotropic and alpha-adrenergic agents. Neuropsychobiology 13:206213. CrossRef Medline

Lothman EW, Bertram EH 3rd (1993) Epileptogenic effects of status epilepticus. Epilepsia 34:S59-S70. CrossRef Medline

Lüttjohann A, van Luijtelaar G (2015) Dynamics of networks during absence seizure's on- and offset in rodents and man. Front Physiol 6:16. CrossRef Medline

Meeren HK, Pijn JP, Van Luijtelaar EL, Coenen AM, Lopes da Silva FH (2002) Cortical focus drives widespread corticothalamic networks during spontaneous absence seizures in rats. J Neurosci 22:1480-1495. Medline

Meeren H, van Luijtelaar G, Lopes da Silva F, Coenen A (2005) Evolving concepts on the pathophysiology of absence seizures: the cortical focus theory. Arch Neurol 62:371-376. CrossRef Medline

Nissinen J, Halonen T, Koivisto E, Pitkänen A (2000) A new model of chronic temporal lobe epilepsy induced by electrical stimulation of the amygdala in rat. Epilepsy Res 38:177-205. CrossRef Medline

Orrù G, Pettersson-Yeo W, Marquand AF, Sartori G, Mechelli A (2012) Using support vector machine to identify imaging biomarkers of neurological and psychiatric disease: a critical review. Neurosci Biobehav Rev 36:1140-1152. CrossRef Medline

Pearce PS, Friedman D, Lafrancois JJ, Iyengar SS, Fenton AA, Maclusky NJ, Scharfman HE (2014) Spike-wave discharges in adult Sprague-Dawley rats and their implications for animal models of temporal lobe epilepsy. Epilepsy Behav 32:121-131. CrossRef Medline

Pearl PL, Holmes GL (2008) Childhood absence epilepsies. In: Pediatric epilepsy: diagnosis and therapy, (Pellock JM, Bourgeois BFD, Dodson WE, Nordli DR, and R Sankar, eds), pp 323-334. New York: Demos Medical.

Racine RJ (1972) Modification of seizure activity by electrical stimulation: II. Motor seizure. Electroencephalogr Clin Neurophysiol 32:281-294. CrossRef Medline

Robinson PF, Gilmore SA (1980) Spontaneous generalized spike-wave discharges in the electrocorticograms of albino rats. Brain Res 201:452-458. CrossRef Medline

Rodgers KM, Bercum FM, McCallum DL, Rudy JW, Frey LC, Johnson KW, 
Watkins LR, Barth DS (2012) Acute neuroimmune modulation attenuates the development of anxiety-like freezing behavior in an animal model of traumatic brain injury. J Neurotrauma 29:1886-1897. CrossRef Medline

Sato S (1983) Generalized seizures: absence. In: Pediatric epileptology: classification and management of seizures in the child, (Dreifus FE, ed), pp 65-91. Boston: John Wright PSG.

Semba K, Komisaruk BR (1984) Neural substrates of two different rhythmical vibrissal movements in the rat. Neuroscience 12:761-774. CrossRef Medline

Semba K, Szechtman H, Komisaruk BR (1980) Synchrony among rhythmical facial tremor, neocortical "ALPHA" waves, and thalamic nonsensory neuronal bursts in intact awake rats. Brain Res 195:281-298. CrossRef Medline

Shaw FZ (2004) Is spontaneous high-voltage rhythmic spike discharge in Long-Evans rats an absence-like seizure activity? J Neurophysiol 91: 63-77. CrossRef Medline

Shultz SR, Cardamone L, Liu YR, Hogan RE, Maccotta L, Wright DK, Zheng P, Koe A, Gregoire MC, Williams JP, Hicks RJ, Jones NC, Myers DE, O’Brien TJ, Bouilleret V (2013) Can structural or functional changes following traumatic brain injury in the rat predict epileptic outcome? Epilepsia 54:1240-1250. CrossRef Medline

Statler KD, Scheerlinck P, Pouliot W, Hamilton M, White HS, Dudek FE (2009) A potential model of pediatric posttraumatic epilepsy. Epilepsy Res 86:221-223. CrossRef Medline

Theodore WH, Porter RJ, Penry JK (1983) Complex partial seizures: clinical characteristics and differential diagnosis. Neurology 33:1115-1121. Medline

Theodore WH, Porter RJ, Albert P, Kelley K, Bromfield E, Devinsky O, Sato S
(1994) The secondarily generalized tonic-clonic seizure: a videotape analysis. Neurology 44:1403-1407. CrossRef Medline

Thompson HJ, Lifshitz J, Marklund N, Grady MS, Graham DI, Hovda DA, McIntosh TK (2005) Lateral fluid percussion brain injury: a 15-year review and evaluation. J Neurotrauma 22:42-75. CrossRef Medline

Van Hese P, Martens JP, Boon P, Dedeurwaerdere S, Lemahieu I, Van de Walle R (2003) Detection of spike and wave discharges in the cortical EEG of genetic absence epilepsy rats from Strasbourg. Phys Med Biol 48:1685-1700. CrossRef Medline

Van Hese P, Martens JP, Waterschoot L, Boon P, Lemahieu I (2009) Automatic detection of spike and wave discharges in the EEG of genetic absence epilepsy rats from Strasbourg. IEEE Trans Biomed Eng 56:706-717. CrossRef Medline

Vanderwolf CH (1975) Neocortical and hippocampal activation relation to behavior: effects of atropine, eserine, phenothiazines, and amphetamine. J Comp Physiol Psychol 88:300-323. CrossRef Medline

Vergnes M, Marescaux C, Micheletti G, Reis J, Depaulis A, Rumbach L, Warter JM (1982) Spontaneous paroxysmal electroclinical patterns in rat: a model of generalized non-convulsive epilepsy. Neurosci Lett 33:97101. CrossRef Medline

Wiest MC, Nicolelis MA (2003) Behavioral detection of tactile stimuli during 7-12 Hz cortical oscillations in awake rats. Nat Neurosci 6:913-914. CrossRef Medline

Williams PA, White AM, Clark S, Ferraro DJ, Swiercz W, Staley KJ, Dudek FE (2009) Development of spontaneous recurrent seizures after kainateinduced status epilepticus. J Neurosci 29:2103-2112. CrossRef Medline

Williamson PD, Spencer DD, Spencer SS, Novelly RA, Mattson RH (1985) Complex partial seizures of frontal lobe origin. Ann Neurol 18:497-504. CrossRef Medline 